\title{
Evaluation of repellent efficacy against Anopheles gambiae s.s.; an anthropophilic malaria vector
}

\section{Avaliação da eficácia de repelentes contra o mosquito Anopheles gambiae s.s.; um vetor da malária antropofílico}

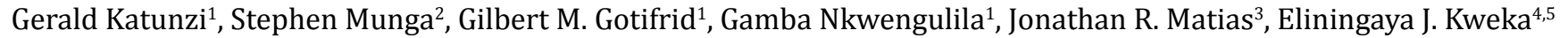

1. University Of Dar Es Salaam, College Of Natural And Applied Sciences, Department of zoology and wildlife conservation. 2. Kenya Medical Research Institute, Centre for Global Health Research, P.0.Box 1578 Kisumu, Kenya. 3. Poseidon Science Foundation, 122 East 42nd Street, Suite 1700, New York, NY USA 10168. 4. Tropical Pesticides Research Institute, Division of livestock and Human Diseases Vector Control, Mosquito Section, P.O.Box 3024, Arusha, Tanzania. 5. Department of Medical Parasitology and Entomology, Catholic University of Health and Allied Sciences, P.0. Box 1464, Mwanza, Tanzania.

\begin{abstract}
Introduction: Reduction of human-vector contact is of epidemiological importance in malaria control. Repellents can be used to complement the existing intervention tools against malaria vectors. Thus, evaluation of efficacy of additional mosquito repellents and /or attractants is of great significance for personal protection tools against malaria vectors. Objective:This study evaluated the repellence efficacy of menthol-propylene-glycol-carbonate (MR08) and Lemon grass (LG) against Anopheles gambiae. Methods: Experiments were performed in a room which was 7.8 meters by 3.9 meters in dimension Three experimental set ups were performed, i) comparison of 10 hours worn sock and unworn sock; ii) comparison of 10 hours worn sock treated with MR08 against worn sock alone, and iii) comparison of 10 hours worn sock treated with LG against worn sock alone. CDC miniature light traps were used to evaluate the recovery of released mosquitoes using both repellents and attractants. Results: After initial trials, a concentration of 500 ppm was selected for all repellents. Among 1800 mosquitoes released into the experimental room, 1230 were recovered by CDC light traps while the remaining 570 were found within the experimental room. Among those collected by light traps, 1185 were collected by traps with worn sock alone. A worn sock treated with either MR08 or Lemon grass significantly repelled An.gambiae compared to worn sock alone. Conclusion: The findings of this study demonstrate that MR08 and lemon grass have inhibition efficiency against mosquito stings but further field evaluations are required for observed findings against wild populations of An.gambiae at lower Moshi using slow release method.
\end{abstract}

Key words Anopheles gambiae s.s., Repellents, Odours, CDC-light trap, Worn sock, Unworn sock, Lemon grass, MR08

\section{Resumo}

Introdução; A redução do contato humano-vector é de importância epidemiológica no controle da malária. Repelentes podem ser usados para complementar os instrumentos de intervenção existentes em relação aos vetores da malária. Assim, a avaliação da eficácia de repelentes e / ou atrativos adicionais para mosquitos é de grande importância como ferramentas de proteção pessoal contra vetores da malária. Objetivo: Este estudo avaliou a eficácia da repelência de mentol-propileno-glicol-carbonato (MR08) e capim limão (LG) contra o Anopheles gambiae. Métodos: Os experimentos foram realizados em um ambiente que tinha de 7,8 metros por 3,9 metros de dimensões. Três passos experimentais foram realizados, i) comparação de 10 horas de meias usadas e meias não usadas; ii) comparação de 10 horas de meias desgastadas tratadas com MR08 contra meia usada sozinha, e iii) de comparação de 10 horas meias desgastadas tratados com LG contra meia usado sozinho. Armadilhas luminosas tipo CDC miniatura foram usadas para recuperação de mosquitos liberados usando ambos os repelentes e atrativos. Resultados: Após os ensaios iniciais, a concentração de 500 ppm foi selecionada para todas as repelentes. Entre 1800 mosquitos liberados na sala experimental, 1.230 foram recuperados por armadilhas luminosas CDC. Entre os dados recolhidos pelas armadilhas luminosas, 1.185 foram recolhidos por armadilhas com meia usada sozinha. A meia desgastada tratada com MR08 ou Lemon grass repeliu significativamente An gambiae em comparação com meia usada sozinha. Conclusão: Os resultados deste estudo demonstram que o MR08 e o capim-limão têm eficiência de inibição contra picadas de mosquitos, mas novas avaliações de campo são necessários para conclusões observadas contra as populações selvagens de Na gambiae com menor Moshi utilizando o método de liberação lenta.

Palavras-chave: Sandfly fauna, Vector of ecology, Leishmaniasis

\section{BACKGROUND}

Anopheles gambiae s.s is the most efficient anthropophilic mosquito species and is endophilic and endophagic ${ }^{1}$. Many field and semi field studies have shown that this species respond to human based semio-chemicals during host seeking process ${ }^{2-5}$. Several volatile compounds released by human body have proved to attract An.gambiae s.s ${ }^{6,7}$.

Thus intervention tools that can incorporate synthetic human odours to deviate mosquitoes from human can reduce humanvector contact and subsequently lead to reduction in malaria transmission ${ }^{8,9}$. Currently, the preferred tools for malaria control are insecticide treated nets and indoor residual spray ${ }^{10}$. Although bed nets are efficacious in reducing human-vector contact, insecticide resistance against many of the insecticide classes used is proving a great challenge to control efforts ${ }^{11}$. Thus, other personal protective materials to complement the existing control tools would be important in the fight against malaria. Consequently, personal protection tools such as topical application of repellents, and burning of the plant leaves, roots and stems have been traditionally used against An.gambiae

Correspondência: Eliningaya J. Kweka . Tropical Pesticides Research Institute, Division of livestock and Human Diseases Vector Control, Mosquito Section, P.O.Box 3024, Arusha, Tanzania.e-amil: pat.kweka@gmail.com

Conflito de interesse: Não há conflito de interesse por parte de qualquer um dos autores.

Recebido em: 9 Fev 2015; Revisado em: 18 Fev 2015; Aceito em: 27 Fev 2015. 
S. $\mathrm{S}^{12,13}$. Mosquito repellent has been defined as substances that once applied on the skin surface or clothes inhibits insect from landing or climbing and subsequently feeding ${ }^{4,15}$. Currently, there are a number of evolving and improved plant based repellents in the market including: Citronella ${ }^{16}$; Eucalyptus ${ }^{17}$ and Ocimum species ${ }^{12,13}$. In a recent study, plant based repellent, MR08 showed a comparative protective efficacy to that of DEET against malaria vectors An.gambiae s.s in both laboratory and field situations ${ }^{14}$. Variations in the protective efficacy among plant based repellents to different mosquito species is due to the varying chemical ingredients of plant extracts and material used to deliver the repellents ${ }^{12,13}$. For example, Menthol propylene glycol carbonate (MR08), a derivative of naturally occurring menthol, showed higher feeding inhibition in laboratory tests against Aedes aegypti and other arthropods, such as sand flies ${ }^{18}$. Specifically, in sand flies, time to first landing was greater than 120 minutes post application with MR08 and this was attributed to a good delivering compound used to avoid evaporation or loss of the plant extract ${ }^{18}$.

Due to the protective efficacy offered by the various repellents, there is renewed interest in developing better ways to dispense repellents or attractants for disease vectors due to ethical issues in protecting human beings against infectious bites 19,20 . Human landing catches have been the gold standard for sampling malaria vectors and evaluating repellents in different ecological settings ${ }^{21}$. However, alternative ways such as traps should be used for evaluating repellents than human landing catches. Traps such as counter-flow geometric trap (MM-X model; American biophysics traps, Corp, USA) and Centre for Diseases Control light traps have demonstrated better efficiency in sampling malaria vectors both in laboratory, semi field and in full field situations ${ }^{5,22}$.

The aim of this study was to compare the repellent efficacy of the MR08 and lemon grass extracts against An.gambiae s.s when applied on a sock with human odour against untreated worn or unworn socks using CDC light trap for capturing released mosquito.

\section{METHODS}

This study was a comparative experiment and was conducted at laboratories of Tropical Pesticides Research Institute, Arusha, Tanzania. The experimental room was kept dark to mimic the 12 hours of natural night conditions with a photo phase which was 12L: 12D based on ordinary natural light.

\section{Traps}

Centre for disease control miniature light traps were used in these experiments to sample An.gambiae s.s. instead of odourbaited counter-flow geometry traps (MM-X model; American Biophysics Corp., RI) which was not available. CDC light traps were modified by removing bulbs so they could not produce light as in MMX-trap, there is not light source. Socks were placed below the fan in CDC light trap hence the human odour was blown from the sock to attract mosquitoes or to repel them from the trap when treated with repellents.

\section{Mosquitoes recovering after release}

Anopheles gambiae s.s were released in a room of $10 \mathrm{~m}$ by $5 \mathrm{~m}$ by $3 \mathrm{~m}$. CDC light trap without a bulb. Each CDC light trap was used to recapture the released An.gambiae mosquitoes with attractant or repellent. The collected mosquitoes from each treatment were collectively used to estimate the recovering rate and the uncaptured were considered lost.

\section{Experimental mosquitoes population rearing}

Blood fed females of An.gambiae s.s. (Kisumu strain) were reared in insectary at a temperature of $27 \pm 2^{\circ} \mathrm{C}$, Relative humidity $80 \%$ and light photo phase of $12 \mathrm{~L}: 12 \mathrm{D}$. The gravid females used were $72 \mathrm{hrs}$ post blood feeding and provided with wet filter paper in a cage to act as oviposition substrate. Filter paper remained wet due to high humidity in the adult mosquito room. Filter papers with mosquito eggs were washed in the hatched larvae and were washed onto a tray $(30 \mathrm{~cm}$ length, $20 \mathrm{~cm}$ width and $3 \mathrm{~cm}$ depth) containing larval rearing water and fed with tetramin fish food (Tetra Werke Company, Inc., Blacksburg, VA, U.S.A) while the emerging pupae were picked twice daily and kept in a cage to emerge into adults. Each tray had a total of 200 larvae. Tetramin fish food was provided at a rate of $0.003 \mathrm{mg} /$ larvae. For three days, females of An.gambiae s.s were fed only on sugar solution. Experimental females were deprived of the sugar solution for 1 hour before the experiment to increase their host seeking aggressiveness. The female adult mosquitoes were selected using aspirator for the experiments and kept in a new cage $(30 \mathrm{~cm} \times 30 \mathrm{~cm} \times 30 \mathrm{~cm})$ in a dark room until experimental release time.

\section{MR08 and Lemon grass dosage assessment and selection}

Before the experiments, the screening of MR08 and lemon grass dosage to be selected for experiments was done by screening a range of dosages. A range of dosages from 100, 200, $300,400,500,600,700,800,900$ and 1000 ppm were selected for been screened for repellence effect against An.gambiae s.l. The solvent used was ethanol which was used in control arm as well. The lowest concentration of MR08 and Lemon grass with inhibition efficiency of $100 \%$ for 30 minutes in cage experiment was considered to be selected for trial. Only one dose was selected from the range of dosages evaluated of each botanical based repellent after attained a protection efficiency of $100 \%$.

\section{Treatment preparation}

Lemon grass essential oil extracted from leaves by steam distillation method was obtained from International Centre of Insect Physiology and Ecology (ICIPE), natural products department while MR08 is menthol propyleneglycol carbonate ${ }^{14}$. Both lemon grass and MR08 that had been stored at $4 \stackrel{\circ}{ } \mathrm{C}$ temperature until when they were used in these experiments. With reference to previous studies, both MR08 and Lemon grass were applied on human skin as mosquito repellents ${ }^{14,16,23}$; $500 \mathrm{ppm}$ of either repellent was used to treat the worn sock during each experiment. This study used a single dose of which 
was a lower concentration provided $100 \%$ protection against mosquitoes in cage experiment. In this study, a worn sock was used to evaluate the repellents so as not to use the human as subject during vector sampling. To avoid contamination while setting up the experiment, a volunteer wore unused gloves each time. Control experiments were set up first, followed with treatment. The active chemical ingredients of both MR08 and Lemon grass essential oil used in this study have been identified and shown elsewhere ${ }^{14,24}$.

Nylon socks have been found to be best in trapping odour from human feet when worn for 8 to 10 hours ${ }^{3,4}$. A sock was worn by the same individual to avoid differential attractiveness and was worn from 8:00 to 0 18:00 hours.

\section{Experimental design}

The following three experimental designs were used:

Evaluation of An.gambiae s.s. attraction by worn against unworn socks

The treatment was set up by placing sock which had been worn for 10 hours in a trap whereas the control was set up using unworn sock placed in another trap and treated the same way. This experiment was replicated six times each, while changing the position of the traps with worn (treatment) and unworn (control) socks daily to avoid biasness in sampling efficiency. In each experiment, a total of 100 unfed females of An.gambiae s.s were released in a room at 18:30 hr when traps had already been set up and switched on. Collection of the trap catches was done at $0730 \mathrm{hr}$.

Evaluation of An.gambiae s.s. attraction by worn sock treated with lemon grass against worn sock alone

The experimental setting, operations, monitoring and mosquito collections from the trap in this experiment was done as described in section (i) above. However, the sock used in this experiment was treated with 500 ppm of lemon grass before the experiment and placed in a trap at the same time with a worn sock without lemon grass (control).

Evaluation of An.gambiae s.s. attraction by worn sock treated with MR08 against worn sock alone

Similarly, the experimental settings and mosquito collections from the traps in this experiment were conducted as described in sections (i) and (ii) above. A sock treated with 500 ppm of MR08 was used in this experiment.

\section{Data Analysis}

Data were entered in Excel sheet and transferred to PWAS statistics Version 18 (SPSS Inc., Chicago, IL) for analysis. Due to variations in data collected from traps, log transformation was done to meet criterion for normality and parametric tests use. Generalized linear model (GLM) Univariate analysis was conducted, position and treatments was considered as fixed factors while, experimental days were considered as a random factor. An.gambiae s.s counts as the dependent variable. A geometric mean was used to calculate the proportion of sampled mosquitoes in each trap for graphical presentation.

\section{RESULTS}

\section{MR08 and Lemon grass dosage assessment and selection}

In protective efficacy of MR08 and Lemon grass, the dosages for both repellents which gave protective efficacy of $100 \%$ for 30 minutes ranged from 500ppm to $1000 \mathrm{ppm}$. The lowest cutoff point was $500 \mathrm{ppm}$ dosage which was selected for trial. The dosage of 100 to $400 \mathrm{ppm}$ of repellents had protective effect of less than $70 \%$ for 30 minutes of exposure.

\section{Mosquitoes recovering in experimental days}

A total number of 1800 unfed 3 day old females of An.gambiae s.s mosquitoes were used during the study period. Among those released, 1230 (68.33\%) were caught by light traps and the rest 570 (31.67\%) were recovered in the experimental room. Among those collected by traps, 1185 (96.3\%) were collected by traps with worn sock alone, 14 (1.1\%) were caught in trap with unworn sock while 17 (1.4\%) were caught in traps with worn sock treated with lemon grass and 14 (1.1\%) were collected from trap with worn sock treated with MR08.

\section{Comparison of the influence of experimental days, treatment and trap position}

Generalized linear model univariate analysis showed that, experimental days (random factor) $(P=0.629)$ and trap positions (fixed factor) ( $P=0.604$ ) had no significant influence on the number of mosquitoes caught by the light traps. However, the number of mosquitoes caught between the treatments and controls were significant different $(P<0.001)$ with more mosquitoes sampled in control trap (Figure 1). Treatment was the only factor which influenced the number of mosquitoes caught in all traps.

Figure 1: Anopheles gambiae s.s. density catch response in traps with different treatments; A) worn sock(WS) against unworn sock(US); B)worn sock treated with MR08(WSMR08) against worn sock alone(WSWMR08), and C) worn sock treated with Lemon grass (WSLG) against worn sock alone(WSWLG).

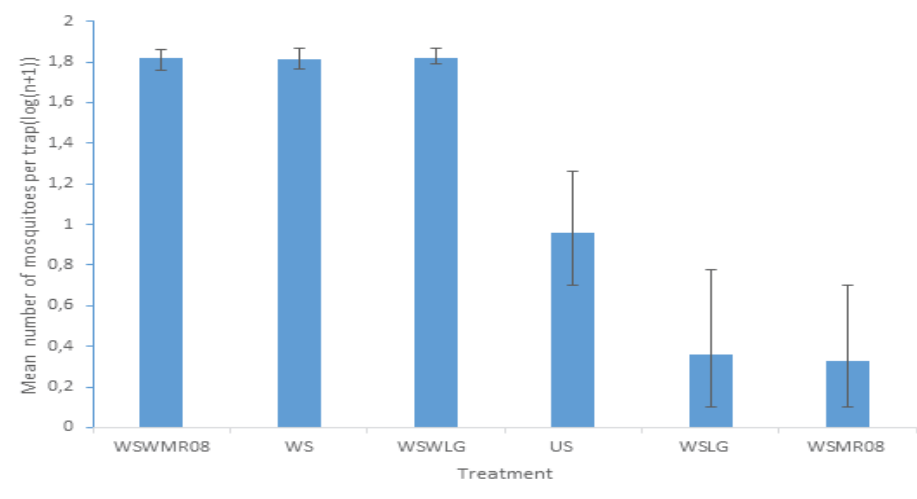




\section{DISCUSSION}

The findings of this study have continued showing that, human odours are attractive to An.gambiae s.s., when lemon grass and MR08 were incorporated in worn socks, the repellent effect was higher, as significantly fewer numbers of An.gambiae s.s. were recovered in treatments arms than in control $(P<0.05)$. The concentrations used for both repellents had protective effect of 70 to $100 \%$. The protection against host seeking mosquitoes observed at a dosage of 500 to $1000 \mathrm{ppm}$. The lowest dosages in this study have potentially reduced mosquitoes from been attracted by a worn sock treated with repellents. This repellent masked the natural human odour and prevented mosquitoes from been attracted, hence pushing mosquitoes away to control trap (with worn sock alone). Previously, host seeking studies conducted under different conditions demonstrated that, total human body odours or extracts of whole odour are potential attractant of An.gambiae s.s. ${ }^{2,4,25,26}$ and singly extracted compounds such as ammonia and lactic acid are attractants. In laboratory cage trials that evaluated protective efficacy of repellents, both MR08 and lemon grass showed significant repellency effect against Aedes aegypti, An.gambiae s.s. and sand flies in the field ${ }^{14,18,23}$. Worn sock or other textile materials have also showed higher efficiency in

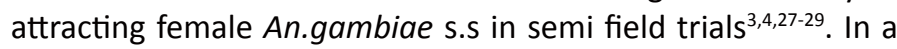
study conducted by Okumu and others using synthetic human odours, the concentration of the odour influenced the number of mosquitoes caught in each trap ${ }^{30}$. Lower concentrations had repellent effects while concentrations above $0.25 \%$, attracted significantly more mosquitoes ${ }^{30}$. This is contrary to our study done using the botanical repellents and worn socks which had the same concentrations throughout the trial. The worn sock without repellents showed higher attraction efficiency to host seeking mosquitoes. These findings have similar trend to previous study which showed the efficiency of a whole human odour in attracting wild and laboratory reared An.gambiae s.s. and field trials of Aedes aegypti ${ }^{5,26,31}$.

There is an increasing pressure on ethical concerns of using human beings in disease vectors sampling i.e. human landing catch $^{19,20}$. Use of trapped human body odours in worn sock have shown promising results in attracting mosquitoes 25 and hence can be used as an alternative for the evaluation of attractants or repellents against An.gambiae s.s, the anthropophilic malaria vectors. The increased and decreased vector densities caught in traps with worn sock and worn sock with repellents respectively are similar to those of previous studies conducted under laboratory and field conditions ${ }^{32}$. Results of the current study indicate that, human odours incorporated in traps can perform as efficiently as when human is used as bait. Other studies, have found human sampled odours to have great impact in attracting mosquitoes in semi-field structures and field evaluated trials ${ }^{31}$. Collection of raw human odour has not been of any harm to volunteers involved since the method is not complicated and collection is done simply by wearing the sock for 8 to 10 hours ${ }^{27}$. This can protect human beings from infection with Plasmodium parasites during sampling. Evidently, in western Kenya it has been found that, among volunteers who were involved in mosquito sampling using human landing catch were found to be malaria negative at entry point, but were infected with parasites during the study data collections sessions ${ }^{33}$.

Due to increased insecticide resistance in An.gambiae s.l. population in the recent past ${ }^{34,35}$, additional tools are required to complement the existing malaria control tools. The possible shift in vector feeding behaviour from endophagy to exophagy, occasioned by intensive interventions coverage indoors can compromise the efficacy of these preferred tools making use of repellents more desirable in addition to the existing tools ${ }^{36}$. Use of MR08 and Lemon grass in lotions have potential vector feeding inhibition to human beings outdoor during mosquitoes host seeking process ${ }^{12,14}$ and indoor where $80 \%$ of malaria transmission occur before going under bed net ${ }^{37}$.

Despite the decrease in malaria vector populations and disease incidences ${ }^{38-40}$; reducing the human-vector contact to zero is still of significant importance in reducing and subsequently eliminating malaria transmission. The efficacy of irritant and repellent effect to mosquitoes shown by MR08 and lemon grass extracts can be of additional value for integrated vectors control and management at this period of insecticides resistance in An.gambiae s.s. ${ }^{34,41}$.

\section{CONCLUSION}

This study has shown that both MR08 and lemon grass when applied as topical repellents can significantly reduce the biting rates from An.gambiae s.s. However, further field studies should be undertaken to assess the currently observed protection efficiency using slow release formulations at community level which shall last overnight in house.

\section{ACKNOWLEDGEMENT}

Authors wish to thank Mr. Adrian Massawe for mosquito rearing and assisting in setting up the experiment. Volunteers who worn the sock throughout the study duration. This study received financial support from Poseidon Science Foundation through JRM.

\section{REFERENCES}

1. Coetzee M, Craig M, le Sueur D. Distribution of African malaria mosquitoes belonging to the Anopheles gambiae complex. Parasitology today (Personal ed 2000 Feb; 16(2):74-77. Pub Med PMID: 10652493.

2. Takken W, Knols BG. Odor-mediated behavior of Afrotropical malaria mosquitoes. Annual Rev Entomol. 1999; 44:131-157. Pub Med PMID: 9990718.
3. Njiru BN, Mukabana WR, Takken W, Knols BG. Trapping of the malaria vector Anopheles gambiae with odour-baited MM-X traps in semi-field conditions in western Kenya. Malar J 2006 May 15; 5:39. doi: 10.1186/1475-2875-5-39. PMCID: PMC 1475871

4. Mukabana WR, Takken W, Coe R, Knols BG. Host-specific cues cause differential attractiveness of Kenyan men to the African malaria vector Anopheles gambiae. 
Malar J 2002 Dec 6; 1:17. doi: 10.1186/1475-2875-1-17. PMCID: PMC 149388.

5. Owino EA, Sang R, Sole CL, Pirk C, Mbogo C, Torto B. Field evaluation of natural human odours and the biogent-synthetic lure in trapping Aedes aegypti, vector of dengue and chikungunya viruses in Kenya. Parasit Vectors. 2014 Sep 23; 7:451. doi: 10.1186/1756-3305-7-451. PubMed PMID: 25246030.

6. Gillies M. The role of carbon dioxide in host finding by mosquitoes. Bull Ent Res 1980 Dec; 70(4):525-532. doi: http://dx.doi.org/10.1017/\$0007485300007811.

7. Mboera LEG, Knols BGJ, Braks MAH, Takken W. Comparison of carbon dioxidebaited trapping systems for sampling outdoor mosquito populations in Tanzania. Med Vet Entomol 2000 Sep; 14(3):257-263. PubMed PMID: 11016432.

8. Griffin JT, Hollingsworth TD, Okell LCet al. Reducing Plasmodium falciparum malaria transmission in Africa: a model-based evaluation of intervention strategies. PLoS Med. 2010 Aug; 7(8): e100034. doi: 10.1371/journal. pmed.1000324.

9. Killeen GF, Seyoum A, Sikaala C, Zomboko AS, Gimming JE, Govella NJ, et al. Eliminating malaria vectors. Parasit Vectors. 2013; 6:172. doi: 10.1186/17563305-6-172. PMCID: PMC 3685528.

10. Sovi A, Azondekon R, Aikpon RY, Govoécthan R, Tokponnan F, Agossa F, et al. Impact of operational effectiveness of long-lasting insecticidal nets (LLINs) on malaria transmission in pyrethroid-resistant areas. Parasit Vectors. 2013; 6:319. doi: 10.1186/1756-3305-6-319. PMCID: PMC 4029312.

11. Trape JF, Tall A, Diagne N, Ndiath O, Ly AB, Faye J, et al. Malaria morbidity and pyrethroid resistance after the introduction of insecticide-treated bednets and artemisinin-based combination therapies: a longitudinal study. The Lancet infectious diseases 2011Dec; 11(12):925-932. doi: 10.10161S14733099(11)70194-3. PubMed PMID: 21856232.

12. Kweka EJ, Mosha FW, Lowassa A, Mahande AM, Massenga CP, Tenu F, et al. Longitudinal evaluation of Ocimum and other plants effects on the feeding behavioral response of mosquitoes (Diptera: Culicidae) in the field in Tanzania. Parasit Vectors. 2008 Oct 22; 1:42. doi: 10.1186/1756.3305-1-42. PubMed PMID: 18945343.

13. Dekker T, Ignell R, Ghebru M, Glinwood R, Hopkins R. Identification of mosquito repellent odours from Ocimum forskolei. Parasit Vectors. 2011 Sep 24; 4:183. doi: 10.1186/1756-3305-4-183. PubMed PMID: 21936953.

14. Kweka EJ, Munga S, Mahande AM, Msangi S, Mazigo HD, Adrias AQ, et al. Protective efficacy of menthol propylene glycol carbonate compared to $\mathrm{N}, \mathrm{N}$-diethyl-methylbenzamide against mosquito bites in Northern Tanzania. Parasit Vectors. 2012 Sep 5; 5:189. PubMed PMID: 22950604.

15. Pennetier C, Chabi J, Martin T, Chandre F, Rogier C, Hougard JM, et al. New protective battle-dress impregnated against mosquito vector bites. Parasit Vectors. 2010 Sep 1; 3:81.doi: 10.1186/1756-3305-3-81. PubMed PMID: 20809969.

16. Phasomkusolsil S, Soonwera M. Insect repellent activity of medicinal plant oils against Aedes aegypti (Linn.), Anopheles minimus (Theobald) and Culex quinquefasciatus Say based on protection time and biting rate. The Southeast Asian J Trop Med Public Health 2010 July; 41(4): 831-840. PubMed PMID 21073057.

17. Trigg JK. Evaluation of a eucalyptus-based repellent against Anopheles spp. in Tanzania. J Am Mosq Control Assoc 1996 June; 12 (2 Pt 1):243-246. PubMed PMID: 8827599.

18. Poseidon science foundation. Poseidon Insect repellent. New York: Poseidon Sciences Group; 2005. 16p. available from: http://www.poseidonsciences.com/ MR08_nontoxic_repellent_menthol_mosquitoes_flies_termites.pdf.

19. Kilama WL. Ethical perspective on malaria research for Africa. Acta tropica 2005 Sep; 95(3):276-284. PubMed PMID: 16023987.

20.Kilama WL. Health research ethics in public health: trials and implementation of malaria mosquito control strategies. Acta Trop 2009 Nov; (112 Suppl 1):S3747. doi: 10.1016/j.actatropica.2009.08.003. Epub 2009 Aug 8. PubMEd PMID: 19665982.

21. Govella NJ, Chaki PP, Mpangile JM, Killeen GF. Monitoring mosquitoes in urban Dar es Salaam: evaluation of resting boxes, window exit traps, CDC light traps, Ifakara tent traps and human landing catches. Parasit Vectors. 2011Mar 21; 4:40. doi: 10.1186/1756-3305-4-40. PubMed PMID: 21418622.

22. Schmied WH, Takken W, Killeen GF, Knols BG, Smallegange RC. Evaluation of two counterflow traps for testing behaviour-mediating compounds for the malaria vector Anopheles gambiae s.s. under semi-field conditions in Tanzania. Malar J. 2008 Nov 3; 7:230. doi: 10.1186/1475-2875-7230. PubMed PMID: 18980669.

23. Phasomkusolsil S, Soonwera M. Efficacy of herbal essential oils as insecticide against Aedes aegypti (Linn.), Culex quinquefasciatus (Say) and Anopheles dirus (Peyton and Harrison). Southeast Asian J Trop Med Public Health. 2011Sep; 42(5):1083-1092. PubMed PMID: 22299433.

24. Barbosa LC, Pereira UA, Martinazzo AP, Maltha CR, Teixeira RR, Melo Ede C. Evaluation of the chemical composition of Brazilian commercial Cymbopogon citratus (D.C.) stapf samples. Molecules 2008 Aug 27; 13(8):1864-1874. PubMed PMID: 18794790.

25. de Jong R, Knols BG. Olfactory responses of host-seeking Anopheles gambiae s.s. Giles (Diptera: Culicidae). Acta Trop 1995 Aug; 59(4):333-335. PubMed PMID: 8533668.

26. Knols BG, de Jong R, Takken W. Differential attractiveness of isolated humans to mosquitoes in Tanzania. Trans R Soc Trop Med Hyg. 1995 Nov-Dec; 89(6):604606. PubMed PMID: 8594668.

27. Mukabana WR, Mweresa CK, Omusula P, Orind BO, Smallegange RC, Van Loon JJ, et al. Evaluation of low density polyethylene and nylon for delivery of synthetic mosquito attractants. Parasit Vectors. 2012 Sep 19; 5:202. doi: 10.1186/1756-3305-5-202. PubMed PMID: 22992518.

28. Nyasembe VO, Teal PE, Mukabana WR, Tumlinson JH, Torto B. Behavioural response of the malaria vector Anopheles gambiae to host plant volatiles and synthetic blends. Parasit Vectors. 2012 Oct 15; 5:234. doi: 10.1186/1756-33055-234. PubMed PMID: 23069316.

29. Mweresa CK, Mukabana WR, Omusula P, Otieno B, Gheysens T, Takken W. Evaluation of textile substrates for dispensing synthetic attractants for malaria mosquitoes. Parasit Vectors. 2014 Aug 16; 7:376. doi: 10.1186/1756-3305-7376. PubMed PMID: 4152566.

30. Okumu FO, Titus E, Mbeyela E, Killeen GF, Moore SJ. Limitation of using synthetic human odours to test mosquito repellents. Malar J 2009 Jul 7; 8:150. doi: 10.1186/11475-2875-8-150. PubMed PMID: 19583848.

31. Matowo N, Moore J, Mapua Set al. Using a new odour-baited device to explore options for luring and killing outdoor-biting malaria vectors: a report on design and field evaluation of the Mosquito Landing Box. Parasit Vectors. 2013 May 4; 6:137. doi: 10.1186/1756-3305-6-137. PubMed PMID: 23642306.

32. Trongtokit $\mathrm{Y}$, Curtis CF, Rongsriyam Y. Efficacy of repellent products against caged and free flying Anopheles stephensi mosquitoes. Southeast Asian J Trop Med Public Health. 2005 Nov; 36:1423-1431. PubMed PMID: 16610644.

33. Gimnig JE, Walker ED, Otieno P Kosgei J, Olang G, Ombok M. Incidence of Malaria among Mosquito Collectors Conducting Human Landing Catches in Western Kenya. Am Trop Med Hyg. 2013 Feb; 88(2):301-308. doi: 10.4269/ ajtmh.2012.12-0209. PubMed PMID: 23249685.

34. Ahoua Alou LP, Koffi AA, Adja MA, Assi SB, Kouassi PK, N'Guessan R. Status of pyrethroid resistance in Anopheles gambiae s. s. M form prior to the scaling up of Long Lasting Insecticidal Nets (LLINs) in Adzope, Eastern Cote d'Ivoire. Parasit Vectors. 2012; 5:289. doi: 10.1186/1756-3305-5-289. PMCID PMC: 3534552.

35. Nardini L, Christian RN, Coetzer N, Ranson H, Coetzee M, Koekemoer LL. 
09 Repellents efficacy against Anopheles gambiae s.s.

Detoxification enzymes associated with insecticide resistance in laboratory strains of Anopheles arabiensis of different geographic origin. Parasites \& vectors 2012 Jun 7; 5:113. doi: 10.1186/1756-3305-5-113. PubMed PMID: 22676389.

36. Padonou GG, Gbedjissi G, Yadouleton Aet al. Decreased proportions of indoor feeding and endophily in Anopheles gambiae s.l. populations following the indoor residual spraying and insecticide-treated net interventions in Benin (West Africa). Parasit Vectors. 2012 Nov 14; 5:262. doi: 10.1186/1756-3305-5262. PubMed PMID: 23151270

37. Seyoum A, Sikaala CH, Chanda J, Chinula D, Ntamatungiro AJ, Hawela M, et al. Human exposure to anopheline mosquitoes occurs primarily indoors, even for users of insecticide-treated nets in Luangwa Valley, South-east Zambia. Parasit Vectors. 2012 May 30; 5:101. doi: 10.1186/1756-3305-101. PubMed PMID: 22647493.

38. Aregawi MW, Ali AS, Al-mafazy AW, Molteni F, Katikiti S, Warsame M, et al. Reductions in malaria and anaemia case and death burden at hospitals following scale-up of malaria control in Zanzibar, 1999-2008. Malar J 2011 Feb 18; 10:46. doi: 10.1186/1475-2875-10-46. PubMed PMID: 21332989.

39. Derua YA, Alifrangis M, Hosea KM, Meyrowitsch DW, Magesa SM, Pedersen EM, et al. Change in composition of the Anopheles gambiae complex and its possible implications for the transmission of malaria and lymphatic filariasis in north-eastern Tanzania. Malar J 2012 Jun 8; 11:188. doi: 10.1186/1475-287511-188. PubMed PMID: 22681999.

40. Meyrowitsch DW, Pedersen EM, Alifrangis M, Scheike TH, Malecela MN, Magesa SN, et al. Is the current decline in malaria burden in sub-Saharan Africa due to a decrease in vector population? Malar J 2011; 10:188. doi: 10.1186/1475-2875-10-188. PMID PMC: 3160426.

41. Yadouleton A, Martin T, Padonou G, Chandre F, Asidi A, Djogbenou L, et al. Cotton pest management practices and the selection of pyrethroid resistance in Anopheles gambiae population in northern Benin. Parasit Vectors. 2011 Apr 13; 4:60. doi: 10.1186/1756-3305-4-60. PubMed PMID: 22681999. 